\title{
Glass ceiling for ethnic minority doctors?
}

\author{
Shailen Sutaria public health registrar ${ }^{1}$, Dominique Allwood public health registrar ${ }^{2}$, Delanjathan \\ Devakumar public health registrar ${ }^{3}$, Jennifer Hall public health registrar ${ }^{3}$, Kate Mandeville public \\ health registrar ${ }^{4}$
}

${ }^{1}$ Department of Primary Care and Public Health, School of Public Health, Faculty of Medicine, Imperial College London, London W6 8RP, UK; ${ }^{2}$ UCL Partners, London, UK; ${ }^{3}$ Institute for Global Health, Faculty of Population Health Sciences, UCL, London, UK; ${ }^{4}$ London School of Hygiene and Tropical Medicine, London, UK

We have enjoyed your series on the "movers and shakers of medicine" over the past year. ${ }^{1}$ However, few of those interviewed are international medical graduates or from a black or minority ethnic group. Our analysis of the 45 medically qualified doctors interviewed found that only three (7\%) were from black or minority ethnic groups and that only one $(2 \%)$ was an international medical graduate from a low or middle income country.

While not claiming to be a representative sample, it does highlight the under-representation of these ethnic minority groups at the highest rungs of UK medicine. A perceived lack of role models may further hamper the ambition of future generations of doctors from these groups. Perhaps The BMJ could lead the way in reflecting achievements of a more diverse selection of the medical workforce?

Competing interests: None declared.

BMJ Confidential. Alan Maryon-Davis: remarkably cheerful, considering. BMJ 2014:349:g6467. (29 October.)

Cite this as: BMJ 2014;349:97084

๑ BMJ Publishing Group Ltd 2014 